\title{
The selection of the Bayesian coincident-index models using model comparison criterion with application in Langat river water quality data
}

\begin{abstract}
In this study, three types of Bayesian coincident-index models were designed based on modification from the so-called Stock-Watson (S-W) index, i.e. the established economic coincident-index. The $\mathrm{S}-\mathrm{W}$ index approach is commonly used to estimate parameters using sufficient time series data in composite index. However, the S-W approach in small time series data sets, irregular observations and unbalanced data across time is not well-studied. Essentially, all the problem situations are easily handled under the proposed class of Bayesian models. Therefore, we were motivated to design a new Bayesian S-W coincident-index with application in river water quality index. The river water quality data has been chosen due to the availability of small, unbalanced data sets and irregular observations at particular time in selected sampling sites. We tested all the new algorithms which are based on the three coincident-index model i.e. model with no lag, model with first order lag in the water quality variables and model with a lag for unobserved water quality index. We used Bayesian model comparison criterion to choose the best coincident-index model. Deviance Information Criteria (DIC) was performed as a criterion for selecting models since its application to a variety of data-diagnostic models was not well-discussed. Sensitivity model analyses for all models were also reported. The results showed that the model with ů prior 2 was the most appropriate for the Langat river water quality data in the selected sampling sites. The results also showed that that the third model with $\stackrel{\mathrm{u}}{\text { prior } 2}$ for all sampling sites was the most adequate.
\end{abstract}

Keyword: Coincident-index model; Langat river; Water Quality Index (WQI) 